\title{
Farklı Kanal İçi Ortamların Apeks Bulucuların Doğruluğu Üzerine Etkisi
}

\author{
Asena Okur(0000-0002-1102-2809) ${ }^{\alpha}$, Tuğrul Aslan(0000-0002-5055-1551) ${ }^{\alpha}$, Burak Sağsen(0000-0002-5274-0380) ${ }^{\alpha}$
}

Selcuk Dent J, 2021; 8: 859-867 (Doi: 10.15311/selcukdentj.734671)

Başvuru Tarihi: 09 Mayıs 2020 Yayına Kabul Tarihi: 05 Şubat 2021

\begin{abstract}
Öz
Farklı Kanal İçi Ortamların Apeks Bulucuların Doğruluğu Üzerine Etkisi

Başarlı bir endodontik tedavi için gerçek kanal uzunluğunun tam olarak belirlenmesi, kök kanalının uygun bir şekilde şekillendirilmesini ve etkili dezenfeksiyonu için en öncelikli şartlardan biridir. Radyografik yöntemle çalışma boyutu tespitindeki problemler nedeniyle elektronik apeks bulucular (EAB) gündeme gelmiştir. Kemo-mekanik şekillendirme esnasında kullanılan yıkama solüsyonları, kök kanal içeriği ve patolojik faktörlerden kaynaklanan kök kanal anatomisindeki değişim EAB'ler tarafından yapılan ölçümlerin doğruluğunu etkileyen faktörler olarak düşünülmüş ve bununla ilgili pek çok çalışma yapılmıştır. Bu derlemenin hedefi, bu literatür bilgisi ışığında, farklı kanal içi ortamların elektronik apeks bulucuların ölçüm hassasiyetine etkilerinin özetlenmesidir.
\end{abstract}

\section{ANAHTAR KELIMELER}

Elektronik apeks bulucu, Çalışma boyu, Farklı kök kanal koşulları

Kanal tedavisi aşamalarının kök kanal sistemi içerisinde tutulması gerektiği kabul edilen bir görüştür ve bu nedenle çalışma boyutu (ÇB) apikal sınırı hassas bir şekilde tespit edilmelidir. Şekillendirme, yıkama ve obturasyon işlemleri apikal daralımda sonlandırılığında ideal bir periapikal doku iyileşmesi sağlanabilir. ${ }^{1}$ Geçmişten günümüze klinik uygulamalarda en yaygın olarak kullanılan yöntem radyografi ile ÇB'nin tespit edilmesidir. Bu yöntemin çeşitli dezavantajları ÇB tespitinde alternatif yöntemlerin aranılmasına neden olmuş ve elektronik apeks bulucular (EAB) ile ÇB tespiti yöntemi gündeme gelmiştir. ${ }^{2}$

Doğru akım kullanımında rezistans esaslı, birinci nesil apeks bulucular periodontal ligamentle oral mukoza arasında var olan 6,5 k $\Omega^{\prime}$ luk elektriksel direnci, hastanın dudağına yerleştirilen negatif uç ile kök kanalındaki pozitif uç olan kanal aleti arasında ölçmektedir. Kanal aleti periodontal ligamente temas edince devre tamamlanmakta ve cihaz ekranı 6,5 k $\Omega^{\prime} \mathrm{u}$ göstermekte ve bu okuma apikal foramen olarak değerlendirilerek ÇB bu ölçümle tespit edilmektedir. ${ }^{3}$

Birinci nesil apeks bulucular ile ortaya çıkan sorunlar, alternatif akım tek frekans empedansı kullanan ikinci nesil apeks bulucuların geliştirilmesine yol açmıştır. Bu aletlerin çalışma prensibinde diş, ucu kapalı uzun dar bir tüp olarak düşünülmektedir. Bu prensip dişin apikal bölgesinde koronal bölgeye göre giderek artan bir elektriksel empedans sergilemesine dayanmaktadır. ${ }^{3}$

\section{ABSTRACT}

The Effect of Different In-Canal Environments On the Accuracy of Apex Locaters

For a successful endodontic treatment, precise determination of the actual canal length is one of the top priorities for proper preparation and effective disinfection of the root canal. Electronic apex locaters (EAL) have been brought to the agenda due to problems in root canal length detection by radiographic method. Irrigation solutions used during chemomechanical preparation, root canal content and change in root canal anatomy due to pathological factors have been considered as factors affecting the accuracy of measurements made by EALs and many studies have been done. The aim of this review is to summarize the effects of different in-canal environments on the measurement accuracy of electronic apex locaters, in light of this literature.

\section{KEYWORDS}

Electronic apex locator, Working length, Different root canal conditions

İkinci nesil elektronik apeks bulucular diğerlerinden farklı olarak dudak klipsi yerine elde tutulan bir parçaya sahiptir. Bu özellik, dudak klipsinin tam temas etmemesinden kaynaklanan hataları engelleyeceği gibi enfeksiyon kontrolünde de önemli rol oynamaktadır. Bu ikinci nesil EAB'ler, doğru bir tespit yapabilmek için kanalda kan gibi elektriksel olarak iletken malzemelerden makul oranda arındırımış olmasını gerektirmekteydi. ${ }^{4}$

Üçüncü nesil EAB'ler (frekans esası) ÇB ölçmek için 2 farklı frekans kullanarak ölçümleri matematiksel ve algoritmik olarak hesaplayarak gerçeğe çok yakın ölçümler verebilmektedirler. ${ }^{5}$ Dördüncü nesil EAB'ler (orantı tip) 5 frekansta empedansı belirleyerek empedans bilgilerini matematiksel bir algoritma olarak işlememekte, bunun yerine rezistans ve kapasitans ölçümü yaparak kök kanalının apikaline olan mesafeyi belirlemek için bunları bir veri tabanı ile karşılaştırmaktadırlar. $^{6}$

2003 yılında geliştirilen 5. nesil EAB'ler devrenin kapasitansını ve direncini ayrı ayrı ölçer ve kök kanalının herhangi bir koşulunda (kuru, ıslak, kanama, salin, EDTA, $\mathrm{NaOCl}$ ) en iyi doğruluğa sahiptirler. ${ }^{7}$ Adaptif özeliğe sahip 6.nesil EAB'ler ise dördüncü ve beşinci nesil apeks bulucuların dezavantajlarına sahip

${ }^{\alpha}$ Erciyes Üniversitesi Diş Hekimliği Fakültesi, Endodonti AD, Kayseri, Türkiye 
olmayıp, hem kuru kanallarda hem de nem, eksuda ve kanama kontrolünün zor olduğu kanallarda ölçüm yapabilmektedirler. ${ }^{7}$

\section{Tablo 1.}

Nesillere göre elektronik apeks bulucu cihazların sınıflandırması ve çalışma prensipleri. ${ }^{8}$

\begin{tabular}{|c|c|c|}
\hline Sinif & Çalışma Prensibi & Cihazlar \\
\hline Birinci Nesil & Rezistans ölç̧ümü & $\begin{array}{l}\text { Root canal meter (Onuki Medical Co, Tokyo, Japonya) } \\
\text { Endodontic meter (Onuki Medical Co, Tokyo, Japonya) } \\
\text { Endo Radar (Electronica liarre, Imola, Italya) } \\
\text { Dentometer (Dahlin ectromedicine, Kopenhag, Danimarka) }\end{array}$ \\
\hline Ikinci Nesil & Empedans Ölçümü & $\begin{array}{l}\text { Sono-Explorer (Hayashi Dental Supply, Tokyo, Japonya) } \\
\text { Endo Cater (Yamaura Seisokushu, Tokyo, Japonya) } \\
\text { Formatron IV (Parkell Dental, Farmingdale, NY, ABD) } \\
\text { Endodontic Meter S III (Onuki Medical Co, Tokyo,Japonya) }\end{array}$ \\
\hline Üçüncü Nesil & $\begin{array}{l}\text { Empedans farkı ya da oranını ölçümü } \\
\text { (2 frekansı aynı anda kullanarak) }\end{array}$ & 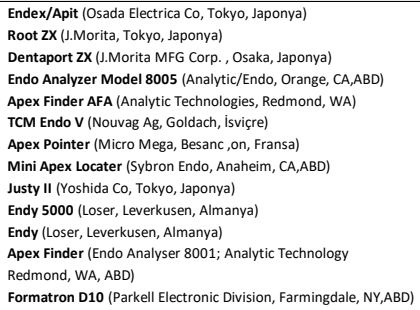 \\
\hline Dördüncü Nesil & $\begin{array}{l}\text { Empedans farkı ya da oranının ölı̧ümü } \\
\text { (iki veye daha çok frekansı farklı } \\
\text { zamanlarda kullanarak) }\end{array}$ & $\begin{array}{l}\text { Bingo 1020/Raypex4 (Foroum Engineering Technologies Rishon } \\
\text { Lesion, Israil) } \\
\text { Raypex } 4 \text { (VDW, Munih, Almanya) } \\
\text { Element Diagnostic Unit\&Apex Locator (Sybron Endo,Anaheim } \\
\text { CA,ABD) } \\
\text { Propex (Dentsply Maillerfer, Ballaiques, Isvicre) } \\
\text { Novapex (Foroum Engineering Technologies Rishon Lesion, Israil) } \\
\text { AFA Apex Finder } 7005 \text { (Analytic/Endo, Orange, CA,ABD) } \\
\text { Ipex (NSK Ltd.Tokyo, Japonya) } \\
\text { Romi Apex D-30 (Romidan LTD, Kiryat-ono, Israil) }\end{array}$ \\
\hline Beşinci Nesil & Kapasitans ve Rezistans ölçümü & $\begin{array}{l}\text { Propex II (Dentsply Maillerfer, Ballaiques, Isviç̧re) } \\
\text { Raypex } 5 \text { (VDW, Munih,Almanya) } \\
\text { I-ROOT (E-Magic Finder)(S-Denti Seoul, Güney Kore) }\end{array}$ \\
\hline Alttncı Nesil & Adaptif tip & $\begin{array}{l}\text { Raypex } 6 \text { (VDW, Munih, Almanya) } \\
\text { Propex Pixi (Dentsply Maillerfer, Ballaiques, isviçre) }\end{array}$ \\
\hline
\end{tabular}

Bir diş bir kondansatöre benzetilecek olursa, dentin ve sement akımın yalıtkanları görevini görürken; periodontal ligament, apikal daralım ve kök kanal sistemindeki bir eğe elektrik iletkenleri görevini görür. Dentin, sement ve kök kanal sistemi içerisindeki herhangi bir ilişkili sıvı veya doku, sistemin izolatörü görevi görecek ve kendi dielektrik sabitine $(\varepsilon)$ sahip olacaktır. $^{9}$

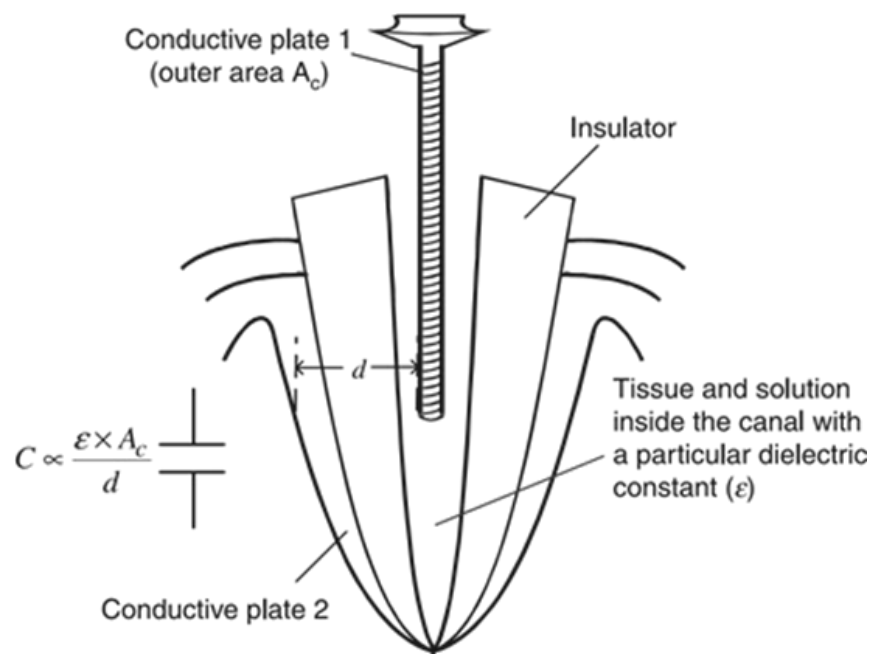

Şekil 1.

Endodontik bir enstrümanın, kök kanal sisteminin ve kondansatör olarak işlev gören periodonsiyumun șematik gösterimi. ${ }^{9}$
Sodyum hipoklorit (NaOCl), klorheksidin $(\mathrm{KH})$, etilendiamin-tetraasetik asit (EDTA), salin, hidrojen peroksit, vs... başarılı bir kök kanal tedavisinin ana basamağı olan kemo-mekanik şekillendirme esnasında en sık kullanılan yıkama solüsyonlarıdır. Bunun yanında, kök kanal sistemi içeriğinde organik doku, kan, eksuda, nem gibi faktörlerle birlikte kök kanal anatomisinde değişime sebep olan patolojik durumlar da bulunabilmektedir. Bu kondansatörün elemanlarından olan kök kanal sitemi içeriğinin ve değişken koşulların bir elektrolit görevi görerek belirli EAB'lerin ölçüm hassasiyetini etkileyen ana faktörlerden olduğu düşünülmektedir. ${ }^{10} \mathrm{Bu}$ yüzden, kök kanal tedavisinde kullanılan farklı yıkama solüsyonlarının ve farklı kanal içi koşulların EAB'lerin ölçüm doğruluğu üzerindeki etkilerini anlamak önemlidir. Bu derlemede, literatürde bu konuda yapılmış çalışmalar ışığında farklı kanal koşullarının farklı EAB'ler ile yapılan ölçümlerin hassasiyetini nasıl etkilediği özetlenmeye çalışılmıştır.

\section{$\mathrm{NaOCl}$}

$\mathrm{NaOCl}$ kemo-mekanik şekillendirme esnasında organik artıkları çözmesi, güçlü antimikrobiyal etkisiyle antiseptik olması, düşük yüzey gerilimi ile dentin duvarlarına kolayca diffüze olabilmesi, kolay elde edilebilmesi ve ucuz olması nedenleriyle en çok kullanılan yıkama solüsyonudur. ${ }^{11} \mathrm{NaOCl}$ solüsyonu kök kanalındaki organik artıklar ile reaksiyona girerek organik dokuları çözdüğü için, bu reaksiyon esnasında $\mathrm{NaOCl}$, aktivasyonunu kaybederken sodyum ve klorür iyonları gibi parçalanma ürünlerine ayrışmaktadır. ${ }^{12}$ Khursheed ve ark. ${ }^{13}$ bu ayrışma nedeniyle yüksek elektro-iletken özellik gösteren \% 3'lük NaOCl'nin Propex apeks bulucunun (Dentsply, Maillefer, Ballaigues, İsviçre) ölçüm esnasında çalışma hassasiyetini olumsuz etkilediğini rapor etmişlerdir.

Birinci ve ikinci nesil elektronik apeks bulucuların elektrolitlerin mevcudiyetinde zayıf doğrulukları olması5, bu dezvantajları Root ZX (Morita, Tokyo, Japonya) gibi üçüncü nesil EAB tarafından aşılmıştır. Bu cihazın minör apikal foramenleri belirlemede \% 82 ile \% 100 arasında doğrulukta olduğu bildirilmiştir 14,15 ve birçok çalışmada altın standart EAB5, ${ }^{16,17}$ olarak kabul edilmiştir. Kang ve ark. ${ }^{18}$, aralarında Root $Z X$ ve Propex'in bulunduğu 7 farklı EAB ile yaptıkları bir araştırmada \% 5.25'lik $\mathrm{NaOCl}$, salin, \% 0,1'lik $\mathrm{KH}$, ve \% 15'lik EDTA varlığında ölçümlerin güvenilir kabul edilebileceğini bildirmişlerdir. Buna karşın, Baruah ve ark. ${ }^{19}$, Root ZX Mini ve Propex Il'nin farklı irriganların farklı sıcaklıklardaki doğruluklarını karşılaştırdıkları çalışmada \% 5'lik $\mathrm{NaOCl}$ (Isıtılımış ve ısıtılmamış) varlığında diğer yıkama solüsyonlarının göre daha fazla varyasyon gösterdiği sonucuna varmışlardır. Tınaz ve ark. ${ }^{20}$ ise Root ZX'in çeşitli $\mathrm{NaOCl}$ konsantrasyonları altında kök ÇB ölçümlerinde doğru sonuç verdiğini rapor etmişlerdir. 
Dördüncü nesil bir EAB olan Raypex 5 (VDW, Münih, Almanya) 2 alternatif akım frekansını (400 $\mathrm{Hz}$ ve 8 $\mathrm{kHz}$ ) kullanır ve bir empedans oranı ile çalışma boyunu belirler. ${ }^{21}$ Üretici firma, Raypex 5 'in, bir seferde sadece bir frekans kullanılmasının ölçüm doğruluğunu ve cihazın güvenilirliğini arttırdığını iddia etmektedir. ${ }^{22}$ Marek ve ark. ${ }^{23}$, Raypex 5'in hassasiyetini ölçmek için yaptıkları bir çalışmada, KH'in jel ve solüsyon formuyla \% 2'lik NaOCl'i karşılaştırmış ve \% 2'lik NaOCl'in ölçüm hassasiyetini büyük ölçüde etkilediğini bulmuşlardır. Gomes ve ark. ${ }^{24}$ ise Raypex 5'in, kullanılan yıkama solüsyonlarından (\% 2.5'lik $\mathrm{NaOCl}$, \% 2'lik $\mathrm{KH}$, \% 17'lik EDTA) bağımsız olarak iyi bir performans gösterdiğini bulmuşlardır.

Khatri ve ark. ${ }^{25}$ eğimli kökler üzerinde oluşturdukları perforasyonların tespiti için VDW Gold(VDW, Münih, Almanya) ve Ipex 'in (NSK, Tochigi, Japonya) doğruluklarını karşılaştırdıkları in vitro çalışmada kök kanalında \% 3'lük $\mathrm{NaOCl}$ varlığının her iki EAB'nin perforasyonu tespit etmede gerçek uzunluktan anlamlı bir fark gösterdiğini belirtmişlerdir. Buna karşın kök kanalında \% $2 \mathrm{KH}$ varlığında ise her iki EAB'nin perforasyon bölgesini doğru bir şekilde tespit ettiğini bildirmişlerdir.25 Chukka ve ark. ${ }^{26}$ ise kök kanalında \% $3 \mathrm{NaOCl}$ ve \% 2'lik $\mathrm{KH}$ varlığında entegre apeks bulucu VDW Gold ile Root ZX Mini'nin doğrulukları arasında bir fark olmadığını ve cihazların tutarlı sonuçlar verdiğini belirtmişlerdir.

Marigo ve ark. ${ }^{27}$ insan kadavra dişleri üzerinde yaptıkları çalışmada kök kanalında \% 5.25'lik $\mathrm{NaOCl}$ varlığında ve yokluğunda Dentaport ZX (Morita) ve Raypex 6'nın doğruluklarını karşılaştırarak 2 EAB'nin her 2 durumda yüksek doğruluklu ölçümler yaptığını ve cihazlar arasında ölçüm hassasiyeti bakımından anlamlı bir fark olmadığını rapor etmişlerdir.

$\mathrm{KH}$

$\mathrm{KH}$, hem kök kanal irrigasyon solüsyonu hem de kanal içi ilaç olarak endodontik tedavide kullanılan güçlü bir antimikrobiyal ajandır. $\mathrm{KH}$ iуi biyouyumluluğu nedeniyle, özellikle NaOCl'ye alerjisi olan hastalarda veya açık apeksli dişlere sahip hastalarda $\mathrm{NaOCl}$ ye bir alternatif olarak önerilmiştir. ${ }^{28}$

Ebrahim ve ark. ${ }^{29}$ üçüncü nesil bir $E A B$ olan Dentaport ZX' in genişletilmiş kanallarda ve farklı irriganların varlığında doğruluğunu değerlendirdikleri bir çalışmada, \% 0.8'lik KH veya RC Prep varlığında sadece apikal çapı büyük olan eğeler kullanıldığında doğru olduğunu ve apikal çapı küçük olan eğelerle ölçülen uzunluğun gerçek uzunluktan daha büyük olduğu sonucuna varmışlardır. Dördüncü nesil bir EAB olan Root ZX II, Dinapadu ve ark. ${ }^{30}$ farklı solüsyonların varlığında \#10 ve \#45 K-tipi el eğesi kullanarak ÇB ölçümü yaptıkları çalışmada, \% 2'lik KH'in \#45 K-tipi el eğesi ile yapılan ölçümde daha doğru sonuç aldıklarını belirtmişlerdir.

Bolbolian ve ark.17 Root ZX'in \% 2.5'lik $\mathrm{NaOCl}$ ve
\% 0.2'lik KH varlığında apikal daralmayı doğru bir şekilde belirleyebildiğini rapor etmişlerdir. ${ }^{31}$ Benzer şekilde, Duran ve ark. da Root ZX'in kök kanalında \% 2.5'lik $\mathrm{NaOCl}$ veya \% 2'lik $\mathrm{KH}$ varlığından etkilenmediğini bildirmişlerdir. Buna karşın, Prasad ve ark. $^{32}$ kök kanalında, aralarında \% 2'lik KH'nin de bulunduğu, farklı solüsyonların varlığında Root ZX ve IRoot'un (S-Denti, Seul, Kore) doğruluğunun anlamlı olarak etkilendiğini $\mathrm{NaOCl}$ ve $\mathrm{CHX}$ gibi daha iletken çözeltilerde büyük sapma meydana geldiğini ve \% 2'lik KH'in en büyük sapmayı gösterdiğini, ancak bunun klinik olarak anlamlı olmadığını belirtmişlerdir.

\section{EDTA}

EDTA, kök kanal dentinindeki kalsiyum iyonları ile oluşturduğu şelasyon özelliği sayesinde dentinin inorganik yapısını uzaklaştırması ve bu etkileşimin sonucu olarak da kök kanalının şekillendirilmesini kolaylaştırması özelliğiyle endodontide yaygın kullanılan bir yıkama solüsyonudur. ${ }^{33}$ Altunbaş ve ark. $^{34}$ Dentaport ZX ve Rooter'ı (Meta Biomed, Cheongwon- Güney Kore) karşılaştırmak için yaptıkları çalışmada Dentaport ZX grubundaki irrigasyon solüsyonları arasında \% 17'lik EDTA'nın en doğru sonuçları verdiğini ve \% 2.5'lik NaOCl'nin en az doğru sonucu verdiğini ifade etmişlerdir; bunun yanında, Rooter grubunda salin ile yapılan ölçümlerin gerçek uzunluğa EDTA ile elde edilenlerden daha yakın olduğunu bulmuşlardır. Dinapadu ve ark. ${ }^{30}$ ise genişletilmiş kanallarda farklı yıkama solüsyonları mevcudiyetindeki Root ZX'in doğruluğuna baktıkları çalışmada apikal çapı küçük ve büyük eğelerle olan ölçümde \% 3'lük $\mathrm{NaOCl}$ ve \% 17'lik EDTA varlığında doğru olduğunu; bununla birlikte, salin ve \% 2'lik KH varlığında apikal çapı büyük eğelerle olan ölçümlerin daha doğru olduğunu ifade etmişlerdir. Prasad ve ark. $^{32}$ Root ZX ve I-Root ile yaptıkları çalışmada, her iki apeks bulucu ile salin ve EDTA'nın gerçek uzunluğa yakın sonuçlar verdiğini bu nedenle, bu solüsyonlar ile elektronik ölçümlerin güvenilir olduğunu belirtmişlerdir. Kök kanalında yıkama solüsyonları varlığında EAB'lerin doğruluğunun incelendiği çalışmalara bakıldığında solüsyonların etkileme dereceleriyle alakalı çelişkili sonuçlar olsa da genel olarak diğer solüsyonlara kıyasla salin ve EDTA varlığında güvenli ölçümler yapılabildiği söylenebilir.

\section{Rezidüel Kalsiyum Hidroksit}

Kalsiyum hidroksit, antibakteriyel ve biyolojik özellikleri nedeniyle endodontide yaygın olarak kullanılmaktadır. ${ }^{35}$ Kök kanal duvarlarındaki varlığı, kanal patlarının dentin tübüllerine nüfuzunu olumsuz etkilemesi nedeniyle kalsiyum hidroksit obturasyondan önce uzaklaştırılmalıdır. ${ }^{36,37}$ Bazı çalışmalarda, kullanılan tekniğe bakılmaksızın kalsiyum hidroksitin kök kanal sisteminden kolayca çıkarılamadığını ve bu nedenle kanal duvarlarında rezidüel olarak bulunabileceğini bildirmiştir. ${ }^{38,39}$ Üstün ve ark. ${ }^{40}$ kök kanalında rezidüel kalsiyum hidroksit varlığının Mini Root ZX'in doğruluğuna etkisini incelemek için 
yaptıkları çalışmada kalan rezidüel miktarın ölçüm doğruluğunu etkilediğini bildirmiştir. Uzunoğlu ve ark. ${ }^{41}$ farklı uzaklaştırma tekniklerinden sonra kök kanalındaki rezidüel kalsiyum hidroksit Root ZX'in ölçüm doğruluğuna baktıkları çalışmada, tekniklerin hiçbirinin kalsiyum hidroksiti tamamen ortadan kaldırmadığını rezidüel miktarın Root ZX'in doğruluğunu olumsuz etkilediği sonucuna varmışlardır. Shojaee ve ark. ${ }^{42}$ ise kök kanalında kalsiyum hidroksitin salin ve \% 5.25 'lik $\mathrm{NaOCl}$ ile çıkarıldıktan sonra Raypex 6 ve Root ZX ile yaptıkları ölçümlerde cihazların doğrulukları arasında istatistiksel olarak anlamlı bir fark olmadığını belirtmiştir.

Kan

Endodontik tedavi basamaklarından biri olan pulpa ekstirpasyonu ve bazı patolojik süreçler kök kanalında kanamaya sebep olur. Kanın elektrolit bir materyal olma özelliğinden ötürü EAB'lerin doğruluğunu etkileyebileceği düşünülmüştür. ${ }^{43,44}$ Saatchi ve ark. ${ }^{45}$ kök kanalında kan varlığının Raypex 5 ve Root ZX'in doğruluğuna etkisini incelemek için yaptıkları in vivo çalışmada, kök kanalında kan bulunmasının EAB'lerin doğruluğunu etkilemediği sonucuna varmışlardır. Bashar ve ark. ${ }^{43}$ yaptıkları in vitro çalışmada Foramatron D 10'un (Parkell Dental, Farmingdale, NY, ABD) kök kanalında kan varlığında çalışma uzunluğunu \pm 0.5 mm'lik klinik olarak kabul edilebilir mutlak hata aralığında \%100 doğrulukla ölçüm yapabildiğini bildirmiştir. Ebrahim ve ark. ${ }^{44}$ yaptıkları in vitro çalışmada kök kanalında kan varlığında Root ZX ile doğru bir ÇB ölçümünün, hazırlanan apikal çapa yakın boyutta ve apikal bölgeye adapte bir eğe ile yapılması gerektiğini belirtmişlerdir. Daimi dişlerde, pulpal durumun (vital veya devital) kök kanalında kanama varlığını etkilemesi nedeniyle, EAB'lerin bu durumdan etkilenip etkilenmediğiyle alakalı Renner ve ark. ${ }^{46}$ yaptıkları in vivo çalışmada pulpal durumun NovApex'in ölçüm doğruluğunun etkilenmediği görüşüne varmışlardır.

Tablo 2.

Kök kanalında irrigasyon solüsyonları, kan ve medikaman varlığının EAB'lerin ölçüm doğruluğuna etkilerinin incelendiği çalışmalar özetlenmiştir.

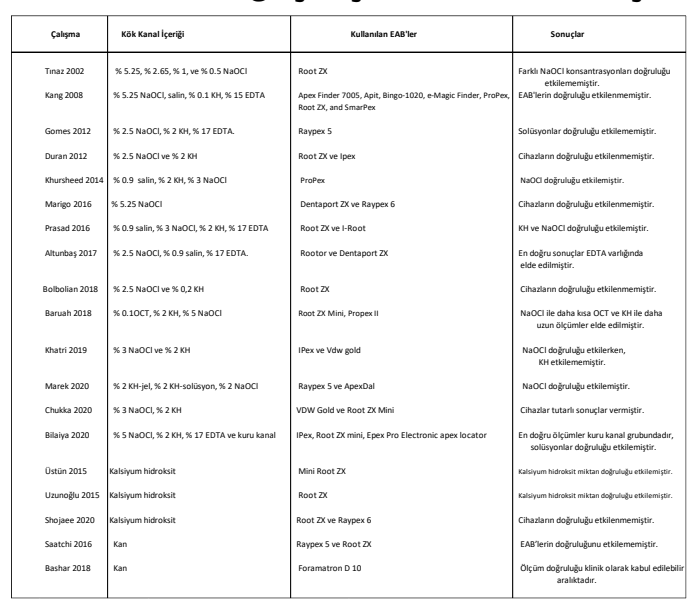

\section{Kök Kanal Perforasyonları}

Kök perforasyonu, kök kanal sistemi ile periodontal dokular arasındaki anatomik olmayan bir iletişim yoludur. Kök perforasyonu, endodontik tedaviden sonra dişin prognozunu olumsuz etkilemesi nedeniyle önemli bir komplikasyondur. Kök kanalında perforasyonun klinik tanısı için pek çok yöntem olmakla birlikte yararlı ve güvenilir olmaları sebebiyle EAB'lerin kullanımı önerilmiştir. ${ }^{47}$ D'Assunção ve ark. ${ }^{47}$ Root ZX II, Mini Apex Locator (SybronEndo, Anaheim, CA, ABD), Root SW'nin (Dental Technology Co, Ltd, Hunan, Çin) kök kanal perforasyonları tespitindeki doğruluklarını inceledikleri çalışmada yüksek doğruluğa sahip olduklarını rapor etmişlerdir. Marroquín ve ark. ${ }^{48}$ metal post yerleştirme esnasında oluşturulan perforasyonları simüle ettikleri bir in vitro çalışmada, perforasyon tespiti için Elements Apex Locator (SybronEndo), ProPex II , Apex NRG (Medic Energy, Tel Aviv,İsrail), Raypex 5 ve Raypex 6 kullanmışlar, ve bütün EAB'lerin klinik olarak kabul edilebilir tespitler yaptıklarını ileri sürmüşlerdir. Moghaddam ve ark. $^{49}$ da EAB'lerin perforasyon tespiti ve tekarlanabilir doğruluklarıyla alakalı yaptıkları araştırmada, NovApex (VDW) ve Smarpex'in (Meta Bıomed) perforasyon saptamada etkili olduklarını belirtmişlerdir. Bilaiya ve ark. $^{50}$ yapay olarak oluşturdukları perforasyonlu dişlerde kök kanalında \% $5 \mathrm{NaOCl}, \% 2 \mathrm{KH}, \% 17$ EDTA varlığında Ipex, Root Zx Mini ve Epex Pro Apex Locator'un doğruluğuna baktıkları in vitro çalışmada tüm cihazların perforasyonları doğru bir şekilde tespit ettiklerini belirtmiştir. Ancak en doğru sonuçların kuru kanal grubunda Root Zx Mini ile yapılan ölçümde olduğunu, EAB'lerin doğruluğunun yıkama solüsyonlarından etkilendiğini ve etkilenme açısından solüsyonlar arasında bir fark olmadığını bildirmiştir.50 Nasiri ve ark. ${ }^{51}$ maksiller molar dişlerin distal kökünde oluşturdukları perforasyonların tespitinde Raypex 6'nın Root ZX'den daha doğru sonuçlar verdiğini belirmiştir. Endodonti uzmanları için bile, kök yüzeyinin bukkal veya lingual yüzeyindeki kök perforasyonlarının klink ve radyografik olarak teşhis edilmesi oldukça zor olmakla birlikte EAB'lerin perforasyon tespitinde etkinlikleri ve yüksek doğrulukları yapılan çalışmalarla da desteklenmiştir, bu noktada EAB'lerin perforasyon tespiti için bir teşhis yöntemi olarak kullanılabileceği söylenebilir.

\section{Horizontal ve Vertikal Kırık}

Vertikal, horizontal veya oblik olarak sınıflandırılabilecek kök kırıkları, klinik endodontik uygulamada teşhis ve tedavi edilmesi en zor vakalar arasındadır. Tanıda dişin radyografik ve görsel muayenesi ve hasta semptomları kullanılabilir, ancak bu yöntemler bazen yetersiz kalmaktadır. Dayandıkları fiziksel ilkeler nedeniyle, EAB'ler, pulpa odasına ulaşan horizontal ve vertikal kök kırıkları, çatlaklar, internal-eksternal kök rezorpsiyonları 
nedeniyle kök kanalı ve periodontal membran arasında oluşan bağlantıyı tespit edebilme yeteneklerinden ötürü bazı çalışmalarda kullanılmıştır. ${ }^{52,53}$

Azabal ve ark. ${ }^{52}$ yapay olarak oluşturulmuş horizontal ve vertikal kök kırıklı dişlerde Justy Il'nin (Yoshida Dentcraft, Tokyo, Japonya) fraktür varlığı tespitindeki doğruluğuna baktıkları çalışmada, Justy II'nin simüle edilmiş horizontal kırıkların pozisyonunu doğru bir şekilde belirleyebildiğini ancak vertikal kırıkların tespitinde güvenilir olmadığını ifade etmiştir. Sykes ve ark.54 Propex II, ve Raypex 4'ün doğruluğuna baktıkları benzer bir çalışmada, iki EAB'nin de ölçümlerde çok güvenilir olduğunu ve kök kırığının yerini belirlemede değerli bir yardımcı olabileceğini belirtmişlerdir. Topuz ve ark. ${ }^{55}$ Tri Auto ZX ( Morita) ve TCM Endo V (Nouvag Ag, Goldach, iviçre) EAB entegreli endodontik motorlarla yaptıkları benzer çalışmada her iki cihazın kök kırıklarını kabul edilebilir şekilde saptadığını, EAB'lerin cihazların auto-reverse modunda daha verimli sonuçlar verdiğini belirtmişlerdir. Goldberg ve ark. ${ }^{56}$ ProPex, NovApex (Forum Technologies, Rishon Le-Zion, İsrail), Root ZX horizontal oblik kök kırığını tespit etmedeki doğruluklarını karşılaştırdıkları in vitro çalışmada EAB'lerin horizontal kök kırığını saptadığını ve aralarında istatiksel olarak anlamlı bir fark olmadığını bulmuşlardır. Beri ve ark. ${ }^{57}$ simüle edilmiş oblik kök kırıkları olan dişlerdeki koronal segmentin apikal sınırını bulmak için ProPex, Root ZX ve Dentaport ZX EAB'lerin doğruluğunu test ettikleri çalışmada kök kırıklarını tespit edebildiklerini ve aralarında istatistiksel olarak anlamlı bir fark olmadığını belirtmişlerdir. Bu sonuçlar; özellikle de horizontal kırıkları tespit etmede EAB'lerin yüksek doğruluklu ölçümler yapması klinik olarak kullanımlarının etkili ve faydalı olacağını göstermektedir.

\section{Apikal Kök Rezorpsiyonu}

Kök rezorpsiyonu, sement ve dentin kaybına yol açan fizyolojik veya patolojik bir süreçtir. Travmatik yaralanma, pulpa veya periodontal ligamanın veya her ikisinin kronik iltihaplanması, apikal daralımın patolojik olarak değişmesi nedeniyle ÇB'nin belirlenmesini son derece zorlaştıracak apikal kök rezorpsiyonu ile sonuçlanır. ${ }^{58}$ Kök rezorpsiyonu, primer dentisyonda fizyolojik bir süreç olarak devam ederken apikal periodontitis nedeniyle de patolojik kök rezorpsiyonu gelişebilmektedir. ${ }^{59}$ Apikal bölgenin şekli, konumu ve boyutu sürekli olarak değişime uğradığından, rezorpsiyon ve sert doku birikimi apikal foramenlerin kesin yerini belirlemeyi zorlaştırır. Bazı çalışmalar EAB'lerin açık apeksli dişlerde çalışma uzunluğunu doğru bir şekilde belirleyemediğini gösterirken ve sadece birkaç çalışma apikal rezorpsiyonlu dişlerde ÇB ölçümü için EAB kullanımının güvenilir olduğunu bildirmiştir.

Stavrionos ve ark. ${ }^{60}$ Raypex 5 'in simüle edilmiş apikal rezorpsiyonlu dişlerde, çalışma uzunluğu ölçme hassasiyetini değerlendirdikleri bir in vitro çalışmada; Raypex 5'in geniş apikal kök rezorpsiyonu dahil olmak üzere çeşitli klinik koşullarda ÇB belirlemede yararlı olabileceğini göstermiştir. Benzer şekilde, yapılan bir başka çalışmada Jadhav ve ark. ${ }^{61}$ Root ZX ve Raypex 6'nın apikal rezorpsiyonlu dişlerde iPex'e kıyasla, çalışma boyu ölçümünde istatistiksel olarak daha yüksek doğruluk ortaya koyduğunu rapor etmişlerdir. Odabaşı ve ark. $^{62}$ rezorpsiyonlu ve rezorpsiyonsuz süt azı dişlerinde Root ZX'in doğruluğunu değerlendirdikleri in vivo çalışmada, her iki grupta ÇB doğru bir şekilde belirlediğini bildirmişlerdir. Nellamakkada ve ark. ${ }^{63}$ in vivo olarak süt 2.azı dişlerinde yaptıkları çalışmada ÇB tespit etme açısından Formatron D10'nun (Parkell Inc., NY, ABD) Propex Pixi'ye oranla daha doğru sonuçlar verdiğini belirtmişlerdir. ${ }^{63}$ Angwaravong ve ark. ${ }^{64}$ benzer çalışmayı in vitro koşullarda yaparak Root ZX'in yüksek doğrulukta ölçümler yaptığını ve apikal üçlüdeki rezorpsiyondan etkilenmediğini belirtmişlerdir.Bir başka benzer çalışmada, Tosun ve ark. ${ }^{65}$ Root ZX'in performansının rezorpsiyondan etkilenmediğini ancak Tri Auto ZX'in etkilendiği sonucuna varmışlardır. ${ }^{65}$ Buna karşın, Mente ve ark. ${ }^{66}$ ise, Tri Auto ZX'in ölçüm doğruluğunun rezorpsiyondan etkilenmediğini ifade etmişlerdir.

\section{Geniş Periapikal Lezyon}

Nekrotik pulpalı ve periapikal lezyonlu dişlerde, enflamatuar apikal kök rezorpsiyonu sıklıkla görülür; sonuç olarak, bu dişlerin apikal daralımı değişebilir ve hatta bazen kaybolabilir. ${ }^{67}$ Ayrıca, geniş periapikal lezyon varlığındaki inatçı periapikal eksüdalar EAB'lerin doğruluğu üzerinde bir etkiye sahip olabilir. ${ }^{68}$ EAB'leri kullanmadan önce inatçı eksüda azaltılmaya çalışılsa da, elektronik ölçümler sırasında kanallar bir miktar eksüda içerebilmektedir. ${ }^{68}$

Çalışkan ve ark. ${ }^{68}$ yaptıkları in vivo çalışmanın sınırlamaları dahilinde, persiste intrakanal eksüdaya sahip geniş periapikal lezyonlu dişlerin çalışma uzunluğunun belirlenmesinde ProPex ve Apex Pointer'in (MicroMega, Besancon, Fransa) güvenle kullanılabileceğini bildirmişlerdir. Bir başka in vivo çalışmada Saatchi ve ark. ${ }^{69}$ apikal periodontitis varlığında ve yokluğunda Raypex 5, Dentaport ZX ve I-Root'un doğruluklarını karşılaştırdıklarında cihazlar arasında bir fark olmadığını apikal periodontitis varlığının ölçüm doğruluğunu etkilemediğini bildirmiştir. Üstün ve ark. ${ }^{70}$ geniş periapikal lezyonlu ve persiste intrakanal eksüdası olan dişlerde ÇB belirlemek için Propex Pixi ve Raypex 6 ile CBCT kullanarak yapılan her iki ölçümün de güvenilir olduğunu belirtmişlerdir. 


\section{SONUÇ}

Kök kanallarındaki farklı ortamların ve içeriklerin varlığında elektronik apeks bulucuların doğru olarak çalışma boyunu tespit etmeleri zorlu bir işlem olabilmektedir. Bu konuda pek çok çalışma geçmişte yapılmış olmakla birlikte, günümüzde de halen yapılmaktadır. Yapılan in vivo ve ex vivo çalışmalar karşılaştırılığında farklı ve tartışmalı sonuçlar olabilmekte, bu durum çalışmaların limitleri dahilinde ve metodolojideki farklılıklarla açıklanırken, özellikle altın standart olarak kabul edilen ve gelişen son teknolojiyle üretilen son nesil EAB'ler (Root ZX, Raypex 6, Propex Pixi, VDW Gold vs.) kabul edilebilir marjin aralıklarındaki doğrulukları sayesinde klinik pratiğinde güvenle kullanılabilmektedir. Bu alanda daha ileri çalışmaların yapılması literatüre ve klinik uygulamalara katkı sağlayacaktır. 


\section{KAYNAKLAR}

1. Ricucci D, Langeland K. Apical limit of root canal instrumentation and obturation, part 2. A histological study. Int Endod J. 1998; 31(6): 394409.

2. Kaval ME, Dönmez H. Elektronik Apeks Bulucular. EÜ Dişhek Fak Derg. 2013; 34(2): 73-8

3. Tınaz C. Kanal tedavisinde çalışma boyutu. Gazi Üniversitesi Diş Hekimliği Fakültesi Dergisi. 2001;18(1):31-7.

4. Welk AR, Baumgartner JC, Marshall JG. An in vivo comparison of two frequency-based electronic apex locators. J Endod. 2003; 29(8): 497-500.

5. Gordon MP, Chandler NP. Electronic apex locators. Int Endod J. 2004; 37(7): 425-37.

6. Khadse A, Shenoi P, Kokane V, Khode R, Sonarkar S. Electronic Apex Locators- An overview. IJCE. 2017; 2(2): 35-40.

7. Dimitrov S, Roshkev D. Sixth generation adaptive apex locator. Journal of IMAB-Annual Proceeding (Scientific Papers). 2009; 15(2009): 75-8.

8. ŞEN ÖG. Endodontide Çalışma Boyunun Doğruluğunu Araştırmada Kullanılan Yöntemler. Türkiye Klinikleri Endodonti-Özel Konular. 2017;3(1):38-41.

9. Nekoofar M, Ghandi M, Hayes S, Dummer P. The fundamental operating principles of electronic root canal length measurement devices. Int Endod J. 2006 Aug;39(8):595-609.

10. Özsezer E, İnan U, Aydın U. In vivo evaluation of ProPex electronic apex locator. J Endod. 2007; 33(8): 974-7.

11. Wesselink $P$, Bergenholtz $G$. Treatment of the necrotic pulp. PROBAB ENG INFORM SCl.2003:156-175

12. Cohen S, Burns R. Pathways of the pulp. St. Louis (MO): Mosby. Elsevier; 2006.

13. Khursheed I, Bansal R, Bansal T, Singh HP, Yadav M, Reddy KJ. A comparative evaluation of working length with digital radiography and third generation apex locator (ProPex) in the presence of various intracanal irrigants: An in vivo/ex vivo study. Dent Res J. 2014; 11(1): 56

14.Swapna DV, Krishna A, Patil AC, Rashmi K, Pai VS, Ranjini MA. Comparison of third generation versus fourth generation electronic apex locators in detecting apical constriction: An in vivo study. J Conserv Dent. 2015; 18(4): 288-91.

15. Stoll $R$, Urban-Klein B, Roggendorf $M$, JablonskiMomeni A, Strauch K, Frankenberger R. Effectiveness of four electronic apex locators to determine distance from the apical foramen. Int Endod J. 2010; 43(9): 808-17.

16.Vasconcelos BCd, Araújo RBR, Luna-Cruz SM, Duarte MAH, Fernandes CAdO. In vivo accuracy of two electronic foramen locators based on different operation systems. Braz Dent J. 2014; 25(1): 12-6.
17.Duran-Sindreu F, Gomes S, Stöber E, Mercadé $M$, Jané $L$, Roig M. In vivo evaluation of the iPex and Root ZX electronic apex locators using various irrigants. Int Endod J. 2013; 46(8): 76974.

18. Kang J-A, Kim SK. Accuracies of seven different apex locators under various conditions. Oral Surg Oral Med Oral Pathol Oral Radiol Endod. 2008; 106(4): 57-62.

19. Baruah Q, Sinha N, Singh B, Reddy PN, Baruah $\mathrm{K}$, Augustine $\mathrm{V}$. Comparative evaluation of accuracy of two electronic apex locators in the presence of contemporary irrigants: An in vitro study. J Int Soc Prevent Communit Dent. 2018; 8(4): 349.

20.Tınaz AC, Sevimli LS, Görgül G, Türköz EG. The effects of sodium hypochloride concentrations on the accuracy of an apex locating device. $J$ Endod. 2002; 28(3): 160-2.

21. Chen E, Kaing S, Mohan H, Ting S-Y, Wu J, Parashos P. An ex vivo comparison of electronic apex locator teaching models. J Endod. 2011; 37(8): 1147-51.

22. Raypex V. apex locator: For successful endodontic treatments. Munich: VDW Endodontic Synergy. 2005:1-4.

23. Marek E, Łagocka R, Kot K, Woźniak K, Lipski M. The influence of two forms of chlorhexidine on the accuracy of contemporary electronic apex locators. BMC Oral Health. 2020; 20(1): 3.

24.Gomes S, Oliver R, Macouzet $C$, Mercadé $M$, Roig M, Duran-Sindreu F. In vivo evaluation of the Raypex 5 by using different irrigants. J Endod. 2012;38(8):1075-7.

25.Khatri MP, Ghivari SB, Pujar M, Faras $R$, Gopeshetti P, Vanti A. Accuracy of two electronic apex locators in locating root perforations in curved canals in dry and wet conditions: A comparative in vitro study. Dent Res J (Isfahan). 2019 Nov 12;16(6):407-412.

26. Chukka RR, Bellam MD, Marukala NR, Dinapadu S, Konda NK, Nagilla J. Efficiency of an integrated apex locator in determining working length in various irrigating solutions: An in vivo study. J Pharm Bioallied Sci. 2020 Aug;12(Suppl 1):S410-S414.

27. Marigo L, Gervasi GL, Somma F, Squeo G, Castagnola R. Comparison of two electronic apex locators on human cadavers. Clin Oral Investig. 2016 Sep;20(7):1547-50.

28.Siqueira JF, de Uzeda M. Intracanal medicaments: evaluation of the antibacterial effects of chlorhexidine, metronidazole, and calcium hydroxide associated with three vehicles. J Endod. 1997; 23(3): 167-9.

29.Ebrahim A, Wadachi $R$, Suda $H$. An in vitro evaluation of the accuracy of Dentaport ZX apex locator in enlarged root canals. Aust Dent J. 2007; 52(3): 193-7. 
30.Dinapadu S, Pasari S, Admala SR, Marukala NR, Gurram S, Peddi R. Accuracy of electronic apex locator in enlarged root canals with different root canal irrigants: an in vitro study. J Contemp Dent Pract. 2013; 14(4): 649.

31.Bolbolian M, Golchin S, Faegh S. In vitro Evaluation of the Accuracy of the Root Zx in the Presence of Naocl 2.5\% and Chlorhexidine 0.2\%. J Clin Exp Dent. 2018; 10(11): 1054-7.

32.Prasad $A B$, Srivastava $H$, Srivastava $A A$, Raisingani $D$. An in vitro evaluation of the accuracy of two electronic apex locators to determine working length in the presence of various irrigants. Ethiop $\mathrm{J}$ Health Sci. 2016; 26(5): 457-62.

33.Aydın M. Endodontik mikrobiyoloji. Ed Alaçam T Endodonti Bölüm. 2000;13.

34. Altunbaş D, Kuştarcı A, Toyoğlu $M$. The influence of various irrigants on the accuracy of 2 electronic apex locators in locating simulated root perforations. J Endod. 2017; 43(3): 439-42.

35. Bergenholtz G, Spångberg L. Controversies in endodontics. Crit Rev Oral Biol Med. 2004; 15(2): 99114.

36. Çalt S, Serper A. Dentinal tubule penetration of root canal sealers after root canal dressing with calcium hydroxide. J Endod. 1999; 25(6): 431-3.

37. Kim S, Kim Y. Influence of calcium hydroxide intracanal medication on apical seal. Int Endod J. 2002; 35(7): 623-8.

38. Rödig T, Vogel S, Zapf A, Hülsmann M. Efficacy of different irrigants in the removal of calcium hydroxide from root canals. Int Endod J. 2010; 43(6): 519-27.

39.Sağsen B, Üstün Y, Aslan T, Çanakçi BC. The effect of peracetic acid on removing calcium hydroxide from the root canals. J Endod. 2012; 38(9): 1197201.

40.Ustun Y, Uzun O, Er O, Canakcı BC, Topuz O. The effect of residual calcium hydroxide on the accuracy of a contemporary electronic apex locator. Acta Odontol Scand. 2015; 73(2): 132-6.

41.Uzunoglu E, Eymirli A, Uyanik MÖ, Çalt S, Nagas E. Calcium hydroxide dressing residues after different removal techniques affect the accuracy of Root-ZX apex locator. Restor Dent Endod. 2015; 40(1): 44-

42. Shojaee NS, Zaeri Z, Shokouhi MM, Sobhnamayan $F$, Adl A. Influence of calcium hydroxide residues after using different irrigants on the accuracy of two electronic apex locators: An in vitro study. Dent Res J (Isfahan). 2020 Jan 21;17(1):48-53

43. Bashar A, Joshi R, Alam M. Accuracy of electronic apex locator for determining the root canal length in presence of blood-an in vitro study. Bangla Med J. 2008; 37(1): 15-8.

44.Ebrahim A, Yoshioka T, Kobayashi C, Suda H. The effects of file size, sodium hypochlorite and blood on the accuracy of Root ZX apex locator in enlarged root canals: an in vitro study. Aust Dent J. 2006; 51(2): 153-7.
45. Saatchi M, Aminozarbian MG, Noormohammadi $H$, Baghaei B. Influence of blood on the accuracy of Raypex 5 and root ZX electronic foramen locators: an in vivo study. Braz Dent J. 2016; 27(3): 336-9.

46. Renner D, Grazziotin-Soares R, Gavini G, Barletta FB. Influence of pulp condition on the accuracy of an electronic foramen locator in posterior teeth: an in vivo study. Braz Oral Res.2012; 26(2): 106-11.

47. D'Assunção FLC, Sousa JCN, Felinto KCA, de Medeiros TC, Leite DT, de Lucena RB, et al. Accuracy and repeatability of 3 apex locators in locating root canal perforations: an ex vivo study. J Endod. 2014; 40(8): 1241-4.

48. Marroquín BB, Fernández CC, Schmidtmann I, Willershausen B, Goldberg F. Accuracy of electronic apex locators to detect root canal perforations with inserted metallic posts: an ex vivo study. Head Face Med. 2014; 10(1): 57.

49. Moghaddam KN, Nazari S, Shakeri L, Honardar K, Mirmotalebi F. In vitro detection of simulated apical root perforation with two electronic apex locators. Iran Endod J. 2010; 5(1): 23-6.

50.Bilaiya S, Patni PM, Jain P, Pandey SH, Raghuwanshi S, Bagulkar B. Comparative Evaluation of Accuracy of Ipex, Root Zx Mini, and Epex Pro Apex Locators in Teeth with Artificially Created Root Perforations in Presence of Various Intracanal Irrigants. Eur Endod J. 2020 Mar 19;5(1):6-9.

51.Nasiri K, Wrbas K-T. Comparing the accuracy of two electronic apex locators in the determination of working length and the detection of root perforations: An in vitro study. Dent Oral Craniofac Res, 2019;5:1-5.

52.Azabal M, Garcia-Otero D, De la Macorra J. Accuracy of the Justy II Apex locator in determining working length in simulated horizontal and vertical fractures. Int Endod J. 2004; 37(3): 174-7.

53.Ebrahim AK, Wadachi R, Suda H. Accuracy of three different electronic apex locators in detecting simulated horizontal and vertical root fractures. Aust Endod J. 2006; 32(2): 64-9.

54.Sykes L, Vally Z. Accuracy of the Raypex-4 and Propex apex locators in detecting horizontal and vertical root fractures: an in vitro study. SADJ. 2006; 61(6): 244-7.

55.Topuz Ö, Uzun Ö, Tinaz AC, Bodrumlu E, Görgül G. Accuracy of two apex-locating handpieces in detecting simulated vertical and horizontal root fractures. J Endod. 2008; 34(3): 310-3

56.Goldberg F, Frajlich S, Kuttler S, Manzur E, Briseño-Marroquín B. The evaluation of four electronic apex locators in teeth with simulated horizontal oblique root fractures. 
57.Beri L, Matariya G. The evaluation of three electronic apex locators in teeth with simulated incomplete oblique root fractures. Journal of the International Clinical Dental Research Organization. 2009;1(3):49.

58. Goldberg F, De Silvio AC, Manfré S, Nastri N. In vitro measurement accuracy of an electronic apex locator in teeth with simulated apical root resorption. Journal of Endodontics. 2002;28(6):461-3. J Endod. 2008; 34(12): 1497-9.

59.Sasaki T, Shimizu T, Watanabe C, Hiyoshi Y. Cellular roles in physiological root resorption of deciduous teeth in the cat. J Dent Res. 1990; 69(1): 67-74.

60.Stavrianos C, Vasiliadis L, Stavrianou I, Louloudiadis A. In vitro Evaluation of the ability of Ray-Pex 5 to determine the working length in teeth with simulated apical root resorption. Balk J Stom. 2009; 13(2): 968.

61. Jadhav GR, Mittal P, Patil V, Kandekar P, Kulkarni A, Shinde S, et al. Accuracy of Different Apex Locators in Teeth with Simulated Apical Root Resorption: an In Vitro Study. Folia Med. 2018; 60(4): 624-31.

62. Enes Odabaş $M$, Bodur $H$, Tulunoğlu Ö, Alaç am A. Accuracy of an electronic apex locator: a clinical evaluation in primary molars with and without resorption. J Clin Pediatr Dent. 2011; 35(3): 255-8.

63. Nellamakkada K, Patil SS, Kakanur M, Kumar RS, Thakur R. A clinical evaluation of two electronic apex locators and conventional radiography in working length determination in primary molar and its influence on children's behavioral responses. J Indian Soc Pedod Prev Dent. 2020;38(2):158.

64.Angwaravong O, Panitvisai P. Accuracy of an electronic apex locator in primary teeth with root resorption. Int Endod J. 2009; 42(2): 115-21.

65.Tosun G, Erdemir A, Eldeniz A, Sermet U, Sener Y. Accuracy of two electronic apex locators in primary teeth with and without apical resorption: a laboratory study. Int Endod J. 2008; 41 (5): 436-41

66. Mente J, Seidel J, Buchalla W, Koch M. Electronic determination of root canal length in primary teeth with and without root resorption. Int Endod J. 2002; 35(5): 447-52.

67. Tronstad L. Root resorption-etiology, terminology and clinical manifestations. Dent Traumatol. 1988; 4(6): 241-52.

68. Çalışkan M, Kaval M, Tekin U. Clinical accuracy of two electronic apex locators in teeth with large periapical lesions. Int Endod J. 2014; 47(10): 920-5.

69.Saatchi M, Aminozarbian MG, Hasheminia SM, Mortaheb A. Influence of apical periodontitis on the accuracy of 3 electronic root canal length measurement devices: an in vivo study. J Endod. 2014 Mar;40(3):355-9.

70.Üstün Y, Aslan T, Şekerci AE, Sağsen B. Evaluation of the reliability of cone-beam computed tomography scanning and electronic apex locator measurements in working length determination of teeth with large periapical lesions. J Endod. 2016; 42(9): 1334-7.
Yazışma Adresi:

Asena OKUR

Erciyes Üniversitesi

Diş Hekimliği Fakültesi

Endodonti AD,

Kayseri, Türkiye

Tel : +90352 2076600 (29128)

E-mail : dtokurasena@gmail.com 